\title{
Effect of aliskiren on proteinuria in non-diabetic chronic kidney disease: a double-blind, crossover, randomised, controlled trial
}

\author{
Sławomir Lizakowski · Leszek Tylicki • Marcin Renke • Przemysław Rutkowski • \\ Zbigniew Heleniak • Maja Sławińska-Morawska • Ewa Aleksandrowicz • \\ Wieslawa Łysiak-Szydłowska • Bolesław Rutkowski
}

Received: 27 July 2011 / Accepted: 20 December 2011/Published online: 28 January 2012

(C) The Author(s) 2012. This article is published with open access at Springerlink.com

\begin{abstract}
Aim To evaluate the proteinuria-lowering effect of a renin inhibitor (aliskiren), compared to placebo and to an angiotensin-converting enzyme inhibitor (perindopril), in patients with non-diabetic chronic kidney disease.

Methods A randomised, double-blind, crossover trial was performed in 14 patients with nondiabetic chronic kidney disease with 24-h mean proteinuria of $2.01 \mathrm{~g}$ (95\% CI, 1.36-2.66) and estimated creatinine clearance of $93 \pm 6.8 \mathrm{ml} / \mathrm{min}$. The study consisted of five treatment periods. The patients were randomly assigned to receive aliskiren $(150 \mathrm{mg})$, aliskiren (300 mg), perindopril (5 mg), perindopril $(10 \mathrm{mg}$ ) or placebo.

Results Aliskiren and perindopril reduced proteinuria. These effects were dose-dependent. Furthermore, 24-h proteinuria was reduced by $23 \%$ (mean $95 \% \mathrm{CI}$; $2-44)$ by treatment with aliskiren $(150 \mathrm{mg})$, by $36 \%$ (95\% CI, 17-55; $P<0.001)$ with aliskiren $(300 \mathrm{mg}$ ),
\end{abstract}

S. Lizakowski $(\square) \cdot$ L. Tylicki · M. Renke

P. Rutkowski · Z. Heleniak · M. Sławińska-Morawska ·

B. Rutkowski

Department of Nephrology, Transplantology and Internal

Medicine, Medical University of Gdańsk. ul, Debinki 7,

80-211 Gdańsk, Poland

e-mail: slizak@gumed.edu.pl

E. Aleksandrowicz · W. Łysiak-Szydłowska

Department of Clinical Nutrition and Laboratory

Diagnostics, Medical University of Gdańsk, Gdańsk,

Poland by $7.1 \%$ (95\% CI, 11-26) with perindopril (5 mg) and by $25 \%(95 \% \mathrm{CI}, 11-39 ; P<0.05)$ with perindopril (10 mg), compared to placebo. No significant difference was found between the effects of aliskiren and perindopril.

Conclusions Aliskiren significantly reduced proteinuria. The antiproteinuric effect is probably similar to that of perindopril, for equivalent hypotensive dosages. The renin inhibitor provides a promising alternative approach for the treatment of patients with chronic proteinuric non-diabetic kidney disease.

Keywords Aliskiren - Renin inhibitor - Proteinuria · Chronic kidney diseases $\cdot$ ACE inhibitor

\section{Introduction}

Proteinuria is a major risk factor for the progression to end-stage renal disease in both diabetic and nondiabetic nephropathies [1]. Angiotensin II and aldosterone are the key players in the development of renal failure, acting directly to promote tissue fibrosis or indirectly on glomerular haemodynamics and proteinuria [2,3]. Therefore, pharmacological inhibition of the renin-angiotensin-aldosterone system (RAAS) may have a beneficial impact on the progression of proteinuria and chronic kidney disease [3, 4].

Various studies have shown that treatment with angiotensin-converting enzyme inhibitors (ACEI) and 
angiotensin II receptor blockers (ARB) reduces both proteinuria and the rate of decline of the glomerular filtration rate in nondiabetic chronic renal disease [57]. Despite recent progress, however, there is still no optimal therapy that can stop the progression of these nephropathies. One reason may be the suboptimal suppression of RAAS activity via ACEI and ARB because a compensatory increase in renin concentration increases levels of angiotensin I and II. Angiotensin II can also be formed using pathways that do not involve the angiotensin-converting enzyme [3]. Therefore, it is necessary to search for alternative therapeutic strategies for blocking RAAS that can further improve renal outcome.

Recently, renin inhibitors, a new class of drugs that selectively inhibits angiotensin II formation at the first step of the RAAS cascade, have been introduced to clinical practice. Aliskiren is the first orally bioavailable direct renin inhibitor approved for the treatment of hypertension. The blood-pressure (BP)-lowering effect of aliskiren is associated with decreased synthesis of angiotensin I from angiotensinogen through inhibition of renin's active enzymatic site [8].

Once-daily oral treatment with aliskiren lowers BP effectively in hypertensive patients, with a safety and tolerability profile comparable with that of a placebo $[9,10]$. In some recent trials, aliskiren has also shown renoprotective potential in patients with type 2 diabetes and albuminuria [11, 12]. To date, however, limited studies have evaluated the renal effects of aliskiren in nondiabetic chronic renal diseases [13, 14]. Consequently, in the present study, we compared the short-term effects of treatment with aliskiren with those of the placebo and ACEI perindopril on proteinuria. In addition, we evaluated the tolerability of aliskiren and its effects on BP.

\section{Materials and methods}

Individuals

Patients were selected from the cohort that attended our renal outpatient department. The inclusion criteria were established as follows: age of 18-65 years, chronic nondiabetic proteinuric nephropathy (chronic kidney disease stage 1-3), stable proteinuria above $500 \mathrm{mg} / 24 \mathrm{~h}$, blood pressure above $125 / 75 \mathrm{~mm} \mathrm{Hg}$ and below 150/95 $\mathrm{mm} \mathrm{Hg}$ and no steroids or other immunosuppressive treatment for a minimum of 6 months before the study. Patients with unstable coronary heart disease or decompensated congestive heart failure in the previous 6 months, patients with an episode of malignant hypertension or stroke in the history, patients with diabetes and patients with an estimated glomerular filtration rate of less than $30 \mathrm{ml}$ per minute per $1.73 \mathrm{~m}^{2}$ of body-surface area were excluded. Stable proteinuria was defined as proteinuria with less than $20 \%$ variability during the 6 months preceding the study.

\section{General protocol}

The study was a randomised, double-blind, controlled crossover trial in which the renal effects of therapy with aliskiren (A), perindopril (P) and placebo (PLA$\mathrm{CEBO})$ were compared. It consisted of a 6-week runin period, 12 weeks of active treatment with aliskiren (Rasilez, Novartis) or perindopril (Prestarium, Servier) and 12 weeks of active treatment with the alternative medication after 12 weeks of placebo administration (Fig. 1). At the beginning of the study, the subjects who met the inclusion criteria began a 6-week run-in period during which the use of any previously used hypotensive agents was stopped.

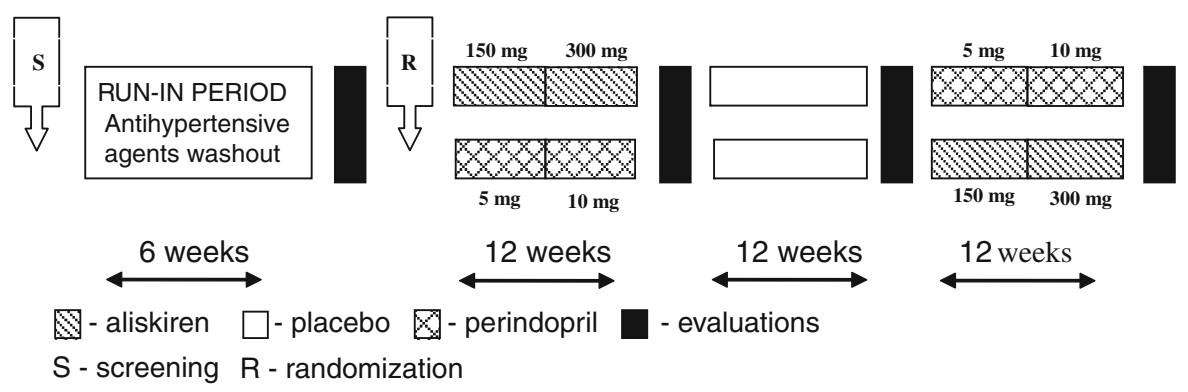

Fig. 1 Scheme of the study 
At the end of the run-in period, the patients were randomly allocated to one of the two treatment sequences: A/PLACEBO/P (sequence 1) or P/PLA$\mathrm{CEBO} / \mathrm{A}$ (sequence 2). The study medications were prepared, labelled and randomised by members of the staff at the Department of Pharmaceutical Technology, Medical University of Gdańsk. Allocation was performed by a person who was independent of the research team and according to a computer-generated randomisation list. For the first 6 weeks of the treatment period, aliskiren was used at a dose of $150 \mathrm{mg}$, and perindopril was administered at a dose of $5 \mathrm{mg}$. The dosages were doubled for the next 6 weeks to the maximal recommended hypotensive dosages of both study medications (i.e., aliskiren at $300 \mathrm{mg}$ and perindopril at $10 \mathrm{mg}$ ). Increasing dosages of aliskiren (above $300 \mathrm{mg}$ ) and of perindopril (up to 12 or $16 \mathrm{mg}$ ) have been shown previously not to further reduce BP $[9,15]$. Drug compliance was assessed by tablet count. The patients were instructed to take the study medication once daily in the morning. At the end of the runin period, the administration of placebo, perindopril $(5 \mathrm{mg})$, perindopril $(10 \mathrm{mg})$, aliskiren $(150 \mathrm{mg})$ and aliskiren $(300 \mathrm{mg})$ was evaluated through measurements of 24-h ambulatory BP, 24-h proteinuria, serum creatinine and potassium levels. Estimated creatinine clearance was calculated as well. The patients were advised not to change their usual daily protein and sodium intake during the study period. The study was approved by the local ethical committee, and the investigated patients all provided their informed consent. The study was registered at http:// www.clinicaltrial.gov (identifier: NCT01219413).

Procedures and laboratory analyses

Ambulatory BP was measured continuously for $24 \mathrm{~h}$ using the Mobil-o-graph (version 12) monitoring system. BP was measured every 15 min during the day (7.00 a.m. to 10.00 p.m.) and every 30 min during the night (10.00 p.m. to 7.00 a.m.). The results of ambulatory BP measurements were analysed to determine mean 24-h systolic BP (SBP) and mean 24-h diastolic BP (DBP). Proteinuria and sodium (Na) and urea excretion were evaluated based on urine collection at $24 \mathrm{~h}$. All of the patients were equipped with a scaled container and were strictly informed as to how to collect urine. Subjects collected two lots of urine at $24 \mathrm{~h}$; using these samples, the mean value of 24-h proteinuria was calculated. The measurements of two samples collected within 1 week were averaged. The patients were asked not to perform heavy physical activity on the days of urine collection. Creatinine clearance was calculated according to the CockroftGault equation.

\section{Statistics}

Data from previous studies were used for the samplesize calculation. The primary end-point of this study was a difference in 24-h proteinuria samples from subjects treated with aliskiren compared with those given a placebo. The baseline 24-h proteinuria level was $2.0 \pm 0.5 \mathrm{~g} / 24 \mathrm{~h}$. Assuming a 30\% reduction in proteinuria after aliskiren treatment [11, 12], we predicted a decrease in proteinuria from 2.0 to $1.4 \mathrm{~g} /$ $24 \mathrm{~h}$ with aliskiren therapy. Thirteen patients had to complete the study to give the study $80 \%$ power to consider differences as statistically significant $(P<0.05,2$-tailed $)$ with an expected within-patient standard deviation of $0.5 \mathrm{~g} / 24 \mathrm{~h}$. The secondary aim was to compare the antiproteinuric effect of aliskiren and perindopril. Because of their skewed distributions, 24-h proteinuria and protein daily intake were logarithmically transformed before statistical analysis and expressed as geometric means and $95 \%$ confidence intervals. Other results are expressed as the mean \pm SEM. The results from the end of the treatment period were compared with those at the end of the placebo period. Differences were assessed using the analysis of variance (ANOVA) for repeated measurements with Bonferroni corrections for paired comparisons. Subsequently, the effects of aliskiren $(150 \mathrm{mg}$ ) were compared with the effects of perindopril $(10 \mathrm{mg})$ using the $t$-test. A $P$ value less than 0.05 (2-tailed) was considered statistically significant. The data were evaluated using the Statistica (version 7.1; StatSoft Inc., Tulsa, OK) software package.

To prevent or limit the possibility of a period effect, we introduced a degree of balance into the study design, with a scheme of randomisation that allowed every treatment to be represented in every period with the same frequency (Fig. 1). To prevent or limit the risk of a carryover effect, we planned each treatment period of 12 weeks. Previous studies showed that the effects of RAAS blockade on proteinuria are fully reversible within 4 weeks [16]. Thus, prolonging each 
treatment period for 12 weeks with alternating placebo periods allowed us to rule out a residual effect of previous treatment at the end of week 12 of another treatment, at which point proteinuria was measured. Grubbs' test was used to detect outliers [17].

\section{Results}

Of the 16 patients who entered the study, 14 (87.5\%) completed the protocol. Two subjects dropped out because of the withdrawal of informed consent, which was not related to the side effects of the therapy. The baseline clinical characteristics of the patients who completed the protocol are listed in Table 1.

\section{4-h ambulatory BP}

SBP and DBP decreased significantly with aliskiren or perindopril treatments compared to those with placebo administration. Aliskiren $(300 \mathrm{mg}$ ) was superior to perindopril $(10 \mathrm{mg})$ for systolic (reduction of $15.6 \mathrm{~mm} \mathrm{Hg} \pm 1.6$ vs. $11.1 \pm 1.5 ; P<0.05)$ and diastolic (reduction of $10.1 \mathrm{~mm} \mathrm{Hg} \pm 1.8$ vs. $6.5 \mathrm{~mm} \mathrm{Hg} \pm 1.1 ; P<0.05$ ) (mean \pm SEM) bloodpressure reduction (Table 2 and Fig. 2). Aliskiren $(150 \mathrm{mg})$ and perindopril $(10 \mathrm{mg})$ provided equal hypotensive efficacy.

\section{4-h proteinuria}

Compared to the placebo values, 24-h proteinuria decreased by $23 \%$ (2-44, mean CI 95\%) following aliskiren $(150 \mathrm{mg})$ treatment, by $36 \%$ (17-55) following aliskiren $(300 \mathrm{mg})$ treatment $(P=0.001)$, by $7.1 \%$ (11-26) following perindopril $(5 \mathrm{mg})$ treatment and by $25.1 \%$ (11-39) following perindopril (10 mg) treatment $(P=0.04)$. In 9 of 14 patients, the maximal reduction in proteinuria was achieved with aliskiren $(300 \mathrm{mg})$ and in another 5 subjects with perindopril $(10 \mathrm{mg})$. The results showed that the reduction in 24-h proteinuria was comparable following equivalent hypotensive doses of both drugs (i.e., aliskiren at $150 \mathrm{mg}$ and perindopril at $10 \mathrm{mg}$ ). In 7 of 14 patients, the reduction in proteinuria was greater with aliskiren at $150 \mathrm{mg}$. In the other 7 patients, the reduction in proteinuria was greater with perindopril at $10 \mathrm{mg}$ (Table 2 and Fig. 3).
Table 1 Patients' characteristic at baseline

\begin{tabular}{|c|c|}
\hline \multicolumn{2}{|l|}{ Parameter } \\
\hline$n$ & 14 \\
\hline Gender: female/male $n$ & $5 / 9$ \\
\hline Age years & $39.0 \pm 3.94$ \\
\hline $\begin{array}{l}\text { Mean systolic blood } \\
\text { pressure } \mathrm{mm} \mathrm{Hg}\end{array}$ & $127 \pm 3.4$ \\
\hline $\begin{array}{l}\text { Mean diastolic blood } \\
\text { pressure } \mathrm{mm} \mathrm{Hg}\end{array}$ & $79 \pm 2.7$ \\
\hline 24-h proteinuria g & $1,77(1,36-2,66)$ \\
\hline Serum creatinine $\mathrm{mg} / \mathrm{dl}$ & $0.96 \pm 0.06$ \\
\hline $\begin{array}{l}\text { Creatinine clearance } \\
\text { [Cockroft-Gault formula] } \\
\mathrm{ml} / \mathrm{min}\end{array}$ & $93 \pm 6,8$ \\
\hline $\begin{array}{l}\text { 24-hour urinary sodium } \\
\mathrm{mmol} / 24 \mathrm{~h}\end{array}$ & $219 \pm 19$ \\
\hline Serum potassium mmol/1 & $4.13 \pm 0.38$ \\
\hline Body mass index $\mathrm{kg} / \mathrm{m}^{2}$ & $26.2 \pm 1.0$ \\
\hline \multicolumn{2}{|l|}{ Diagnosis: $n$} \\
\hline Mesangial glomerulonephritis & 3 \\
\hline $\begin{array}{l}\text { Mesangiocapillary } \\
\text { glomerulonephritis }\end{array}$ & 1 \\
\hline Membranous glomerulonephritis & 3 \\
\hline IgA nephropathy & 1 \\
\hline $\begin{array}{l}\text { Unknown nondiabetic } \\
\text { proteinuric chronic } \\
\text { kidney diseases }\end{array}$ & 6 \\
\hline \multicolumn{2}{|l|}{$\begin{array}{l}\text { Background hypotensive } \\
\text { therapy: } n\end{array}$} \\
\hline ACEI and ARB & 7 \\
\hline ACEI (alone) & 4 \\
\hline No hypotensive therapy & 3 \\
\hline
\end{tabular}

To convert serum creatinine in $\mathrm{mg} / \mathrm{dL}$ to $\mu \mathrm{mol} / \mathrm{L}$, multiply by 88.4; eGFR in $\mathrm{ml} / \mathrm{min} / 1.73 \mathrm{~m}^{2}$ to $\mathrm{ml} / \mathrm{s} / 1.73 \mathrm{~m}^{2}$, multiply by 0.01667 ; data are expressed as mean \pm SEM or geometric mean $(95 \% \mathrm{CI})$

Renal function, sodium and protein intake

Renal function as assessed by means of creatinine clearance remained stable during the study. There were no differences in sodium or protein intake between treatment periods (Table 2).

Adverse effects: serum potassium concentration

Aliskiren and perindopril were well tolerated by the patients. Adverse effects were not reported. The serum potassium concentration was unchanged during the study period (Table 2). 


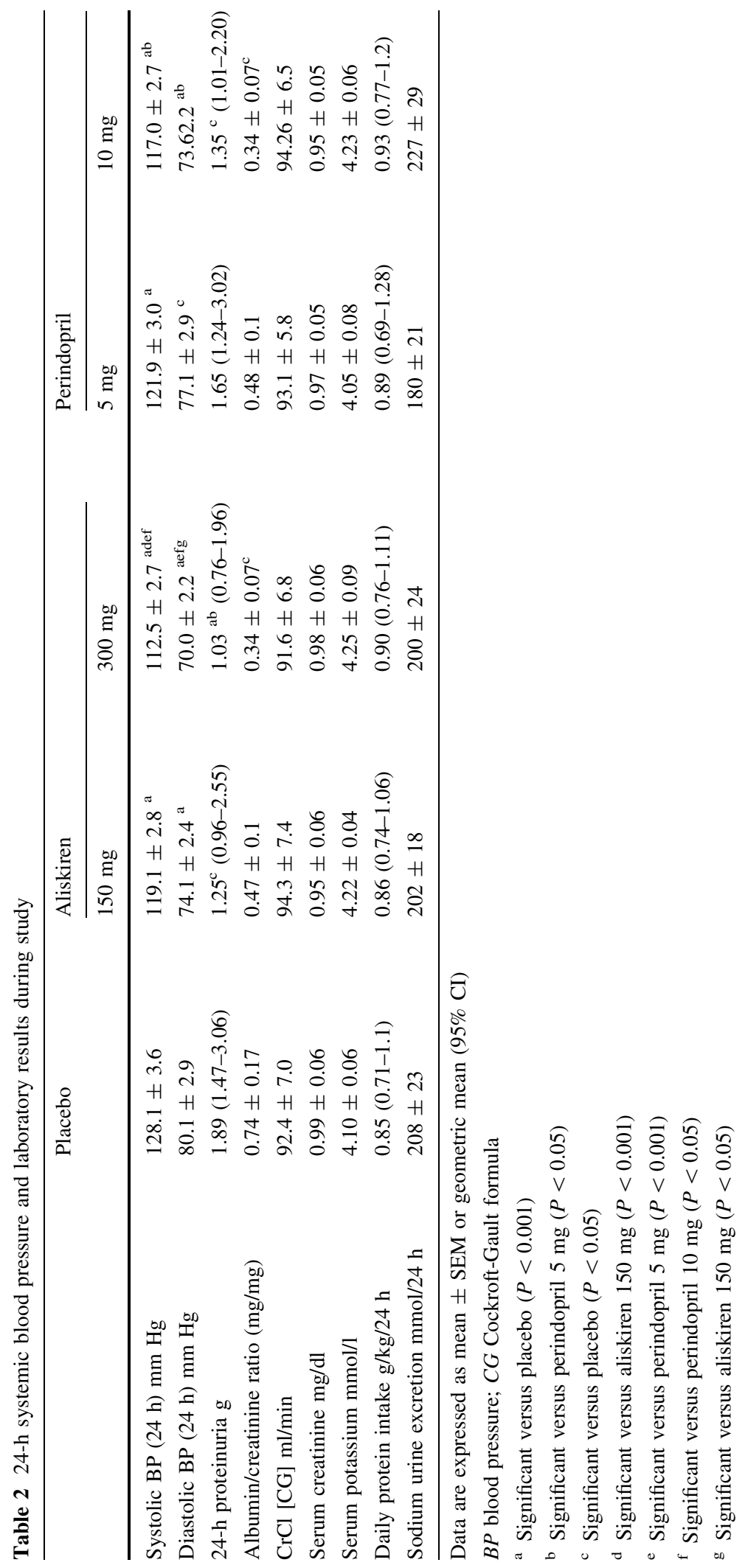


Fig. 2 Systolic (a) and diastolic (b) blood pressure during study
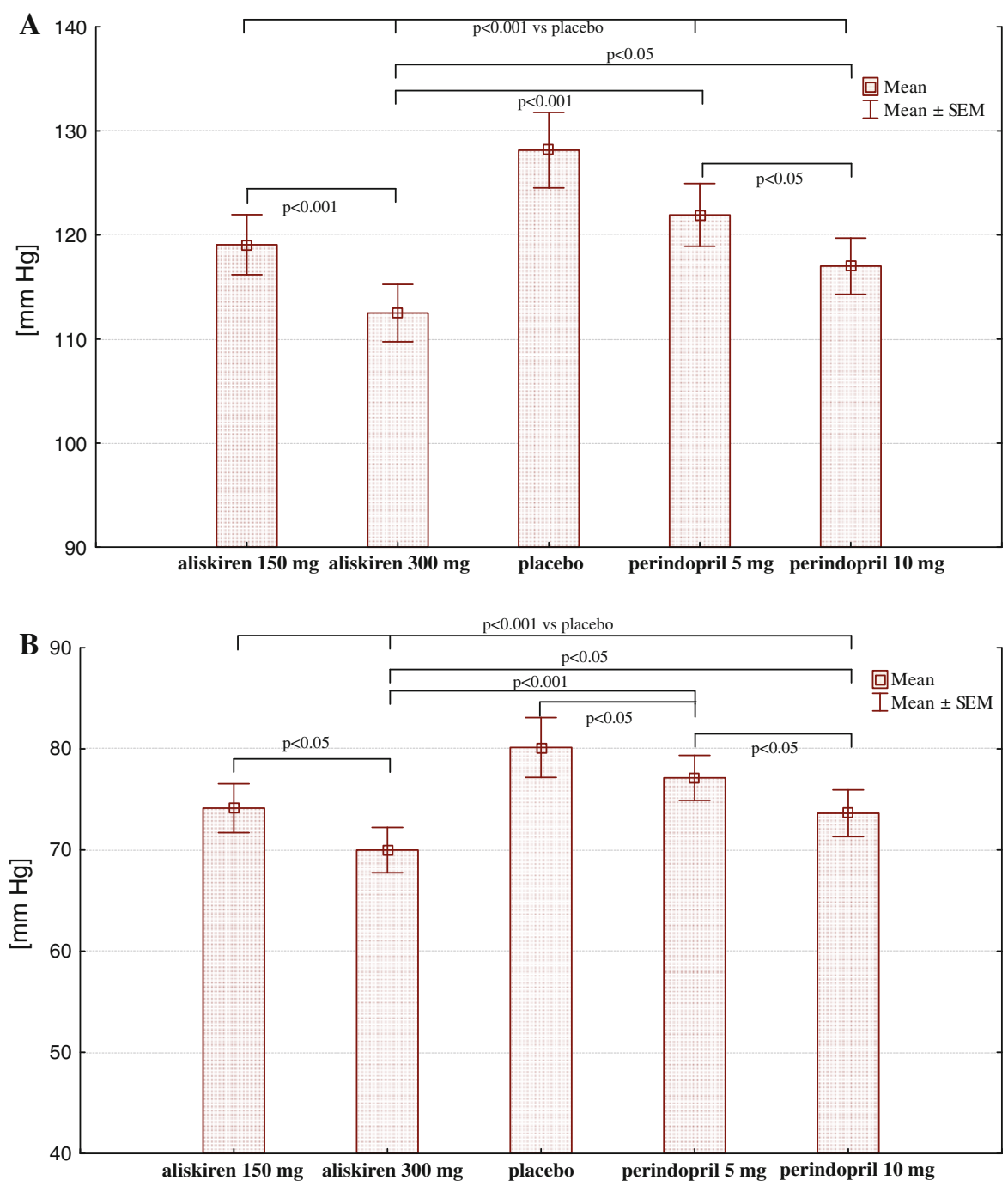

\section{Discussion}

In this exploratory short-term study, we demonstrated that treatment with a renin inhibitor, aliskiren, significantly reduced proteinuria in patients with nondiabetic chronic kidney diseases. Preclinical studies have shown that aliskiren, like other RAAS inhibitors, has antiproteinuric effects in both diabetic and nondiabetic models of chronic kidney disease. When it was compared with ACEI or ARB in these models, the renoprotective effects were approximately equal [18-20]. Clinical data on this point are still very limited and mainly focused on patients with diabetic nephropathy. In the AVOID trial, Parving et al. evaluated the effects of dual blockade of the RAAS with aliskiren and losartan in patients with hypertension and type 2 diabetes with nephropathy.
Patients were maintained on losartan (100 mg daily) for the duration of the study and were randomised to receive a 6-month treatment with aliskiren or a placebo. After 3 months of treatment with aliskiren at $150 \mathrm{mg}$, albuminuria had been decreased by $11 \%$. Increasing the dose of aliskiren to $300 \mathrm{mg}$ caused a further decrease in the albuminuria to $20 \%$ of the baseline level [11]. In a double-blind, randomised, crossover study involving patients with type 2 diabetes, hypertension, and albuminuria, Persson et al. demonstrated that aliskiren treatment reduced albuminuria by $48 \%$ compared with a placebo. This reduction was not significantly different from the 58\% reduction achieved with irbesartan treatment [21].

Studies concerning the above issue in patients with nondiabetic CKD are very limited. In two small 


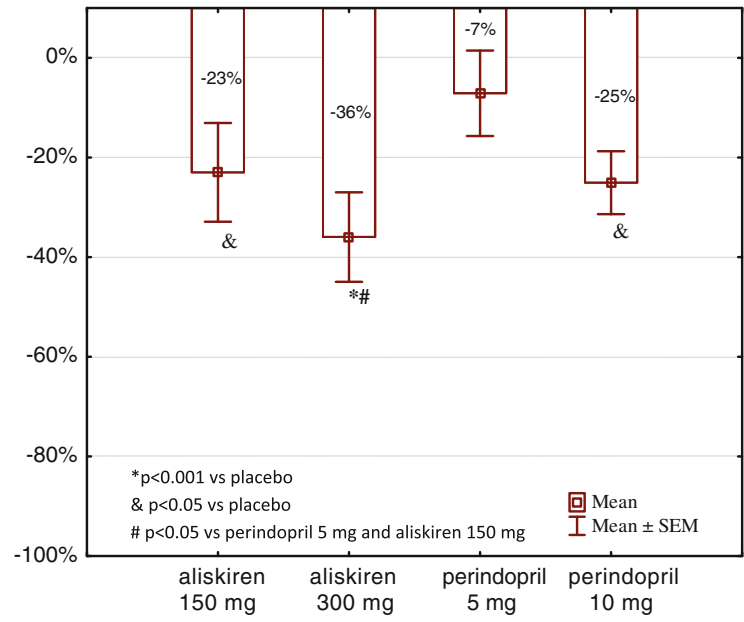

Fig. 3 Changes in 24-h proteinuria versus placebo during study (mean $\pm \mathrm{SEM}$ ). ${ }^{*} P<0.001$ versus placebo, $P<0.05$ versus placebo, ${ }^{\#} P<0.05$ versus perindopril $5 \mathrm{mg}$ and aliskiren $150 \mathrm{mg}$

studies, the addition of aliskiren to ARB was shown to decrease proteinuria in subjects with IgA nephropathy and various forms of primary glomerulonephritis $[13,14]$. Aliskiren confers an antiproteinuric effect in patients who exhibit significant residual proteinuria despite having received the recommended renoprotective treatment. To our best knowledge, this is the first clinical study to perform a head-to-head comparison of renal effects between renin inhibitors and ACEI in patients with nondiabetic renal disease. Specifically, the study involved mainly patients with normal and high-normal systemic BP. Aliskiren was shown to reduce proteinuria compared to a placebo. The effect was dose dependent, as in the case of perindopril therapy.

In this study, we have shown that treatment with a renin inhibitor, aliskiren, significantly reduced proteinuria. In equivalent hypotensive doses, aliskiren seems to decrease proteinuria at least as efficiently as therapy with ACEI, perindopril. However, the study may have lacked sufficient power to identify small differences in the renal effects of these medications as significant. Increasing the dosage of aliskiren from 150 to $300 \mathrm{mg}$ induced a further $13 \%$ decrease in protein excretion. Given the prognostic value of proteinuria for long-term renal outcome, it may be advisable to use aliskiren in therapeutic dosages that are as high as possible. This suggestion applies also to proteinuric patients with normal blood pressure. The therapy with aliskiren even in maximal dosages of
$300 \mathrm{mg}$ was well tolerated by all patients. Systolic blood pressure did not decrease below $110 \mathrm{~mm} \mathrm{Hg}$. Of particular interest may be the renal effects of aliskiren at levels that exceed maximal recommended dosages.

Aliskiren was shown to be a more potent hypotensive drug than perindopril. At the maximal registered doses, aliskiren at $300 \mathrm{mg}$ was superior to perindopril at $10 \mathrm{mg}$ for the reduction in systolic and diastolic BP. This finding is in line with comparative studies showing that aliskiren may be slightly more effective in lowering BP than ACEI [22, 23]. A greater reduction in BP leads to greater proteinuria reduction. In our study, aliskiren at $300 \mathrm{mg}$ reduced proteinuria to a greater extent than perindopril at $10 \mathrm{mg}$; however, the sample size of the study was too small to identify this trend as significant. One may not exclude, however, that this effect was also the consequence of more comprehensive suppression of RAAS components during aliskiren treatment. Direct renin inhibitors may provide more complete and thus more effective blockade of the RAAS than treatment with ACEI or ARB. Fisher et al. [24] showed that maximal doses of aliskiren increased renal blood flow to levels twofold greater than those achieved by maximal doses of ACEI, captopril; the effect was $40 \%$ stronger than that achieved by ARB.

It is unlikely that other confounders influenced the study outcome. The five treatment periods did not differ with respect to renal function or protein intake. To reduce the influence of sodium-dependent mechanisms on the study results, no diuretics were allowed during the study. In addition, patients were instructed not to change their daily sodium intake during the study period. Sodium excretion was monitored and found not to change during all study phases. Our exploratory study had enough power to detect a significant difference in antiproteinuric effect between aliskiren and placebo but lacked sufficient power to detect such a difference between both dosages of each medication. A potential limitation may also be the fact that patients with severe nephrotic syndrome or impaired renal function were not evaluated. Furthermore, a comparable reduction in proteinuria over 6 weeks may not necessarily suggest that aliskiren has a similar long-term effect to an ACEI on the rate of GFR decline.

Aliskiren therapy was well tolerated by patients with no incidence of hyperkalaemia or acute renal failure. There were also no differences between 
aliskiren and perindopril with respect to changes in serum potassium or renal function.

In conclusion, aliskiren significantly reduced proteinuria in a dose-dependent manner. This effect is probably at least as effective as perindopril in equal hypotensive doses. Given the strong prognostic value of proteinuria for evaluating renal outcome, aliskiren provides a promising alternative approach for the treatment of patients with nondiabetic chronic kidney diseases, even in those without hypertension.

Acknowledgments The study was supported by a grant from the Polish Committee for Scientific Research via the Medical University of Gdańsk (ST-4). The authors thank NOVARTIS Poland and SERVIER Poland for providing the drugs.

Conflict of interest The authors declare that they have no conflict of interest.

Open Access This article is distributed under the terms of the Creative Commons Attribution License which permits any use, distribution, and reproduction in any medium, provided the original author(s) and source are credited.

\section{References}

1. Remuzzi G, Bertani T (1990) Is glomerulosclerosis a consequence of altered glomerular permeability to macromolecules? Kidney Int 38:384-394

2. Nakamura T, Fujiwara N, Sato E, Ueda Y, Sugaya T, Koide $\mathrm{H}$ (2010) Renoprotective effects of various angiotensin II receptor blockers in patients with early-stage diabetic nephropathy. Kidney Blood Press Res 33:213-220

3. Tylicki L, Larczynski W, Rutkowski B (2005) Renal protective effects of the renin-angiotensin-aldosterone system blockade: from evidence-based approach to perspectives. Kidney Blood Press Res 28:230-242

4. Siamopoulos KC, Kalaitzidis RG (2008) Inhibition of the renin-angiotensin system and chronic kidney disease. Int Urol Nephrol 40:1015-1025

5. The GISEN group (Gruppo Italiano di Studi Epidemiologici in Nefrologia) (1997) Randomised placebo-controlled trial of effects of ramipril on decline in glomerular filtration rate and risk of terminal renal failure in proteinuric, non-diabetic nephropathy. Lancet 349:1857-1863

6. Maschio G, Alberti D, Janin G et al (1996) Effect of the angiotensin-converting-enzyme inhibitor benazepril on the progression of chronic renal insufficiency. The angiotensinconverting-enzyme inhibition in progressive renal insufficiency study group. N Engl J Med 334:939-945

7. Tylicki L, Rutkowski P, Renke M, Rutkowski B (2002) Renoprotective effect of small doses of losartan and enalapril in patients with primary glomerulonephritis. Am J Nephrol 22:356-362

8. Nussberger J, Wuerzner G, Jensen C, Brunner HR (2002) Angiotensin II suppression in humans by the orally active renin inhibitor Aliskiren (SPP100): comparison with enalapril. Hypertension 39:E1-E8

9. Gradman AH, Schmieder RE, Lins RL, Nussberger J, Chiang Y, Bedigian MP (2005) Aliskiren, a novel orally effective renin inhibitor, provides dose-dependent antihypertensive efficacy and placebo-like tolerability in hypertensive patients. Circulation 111:1012-1018

10. Stanton A, Jensen C, Nussberger J, O'Brien E (2003) Blood pressure lowering in essential hypertension with an oral renin inhibitor, aliskiren. Hypertension 42:1137-1143

11. Parving HH, Persson F, Lewis JB, Lewis EJ, Hollenberg NK (2008) Aliskiren combined with losartan in type 2 diabetes and nephropathy. N Engl J Med 358:2433-2446

12. Persson F, Rossing P, Schjoedt KJ et al (2008) Time course of the antiproteinuric and antihypertensive effects of direct renin inhibition in type 2 diabetes. Kidney Int 73:14191425

13. Tang SC, Lin M, Tam S, et al (2011) Aliskiren combined with losartan in immunoglobulin a nephropathy: an openlabeled pilot study. Nephrol Dial Transplant. doi:10.1093/ ndt/gfr349

14. Moriyama T, Tsuruta Y, Kojima C, et al (2011) Beneficial effect of aliskiren combined with olmesartan in reducing urinary protein excretion in patients with chronic kidney disease. Int Urol Nephrol. doi:10.1007/s11255-011-9991-0

15. Chrysant SG, McDonald RH, Wright JT, Barden PL, Weiss RJ (1993) Perindopril as monotherapy in hypertension: a multicenter comparison of two dosing regimens. The perindopril study group. Clin Pharmacol Ther 53:479-484

16. Bianchi S, Bigazzi R, Campese VM (2005) Antagonists of aldosterone and proteinuria in patients with CKD: an uncontrolled pilot study. Am J Kidney Dis 36:45-51

17. Grubbs FE (1969) Procedures for detecting outlying observations. Technometrics 11:1-21

18. Feldman DL, Jin L, Xuan H et al (2008) Effects of aliskiren on blood pressure, albuminuria, and (pro)renin receptor expression in diabetic TG(mRen-2)27 rats. Hypertension 52:130-136

19. Pilz B, Shagdarsuren E, Wellner M et al (2005) Aliskiren, a human renin inhibitor, ameliorates cardiac and renal damage in double-transgenic rats. Hypertension 46:569-576

20. Kelly DJ, Zhang Y, Moe G, Naik G, Gilbert RE (2007) Aliskiren, a novel renin inhibitor, is renoprotective in a model of advanced diabetic nephropathy in rats. Diabetologia 50:2398-2404

21. Persson F, Rossing P, Reinhard H et al (2009) Renal effects of aliskiren compared with and in combination with irbesartan in patients with type 2 diabetes, hypertension, and albuminuria. Diabetes Care 32:1873-1879

22. Uresin Y, Taylor AA, Kilo C et al (2007) Efficacy and safety of the direct renin inhibitor aliskiren and ramipril alone or in combination in patients with diabetes and hypertension. J Renin Angiotensin Aldosterone Syst 8:190-198

23. Andersen K, Weinberger MH, Egan B et al (2008) Comparative efficacy and safety of aliskiren, an oral direct renin inhibitor, and ramipril in hypertension: a 6-month, randomized, double-blind trial. J Hypertens 26:589-599

24. Fisher ND, Jan Danser AH, Nussberger J, Dole WP, Hollenberg NK (2008) Renal and hormonal responses to direct renin inhibition with aliskiren in healthy humans. Circulation 117:3199-3205 